\title{
THE CHEMISTRY OF SUBSTANCES AND THE PHILOSOPHY OF MASS TERMS*
}

\section{INTRODUCTION}

In this paper I will contrast scientific knowledge about chemical substances such as water with the recent philosophical discussion about natural kinds stimulated by lectures and publications of Kripke, Putnam, and others. ${ }^{1}$ My conclusion will be that in order to define or designate the referent of a mass term, we have to look for macroscopic sameness, not for underlying structure. The latter may provide a more sophisticated explanation of the structure of matter, but underlying structure does not show the way to the "true" essence of a particular substance. Further, as an explanation of the kind of laws scientists discover, it can be instructive to consider the possibility of there being necessary a posteriori statements (in the sense proposed by Kripke), but in this category of statements we should then not only place, for example,

(1) water is $\mathrm{H}_{2} \mathrm{O}$,

but also ${ }^{2}$

(2) liquid water has minimum density at $3.98^{\circ} \mathrm{C}$.

Furthermore, it is not the task of the scientists to find essences that fit the philosopher's ontological framework, but to give better descriptions of what there is. What there is, is substances and/or natural kinds and compounds thereof. A philosophical theory of natural kinds should be independent of any possible scientific explanation of the structure of matter. ${ }^{3}$

Firstly, a few terminological matters are in order. In the philosophical literature the term 'natural kind' usually refers to both biological natural kinds, such as tigers, and to so called stuffs, such as water and gold. I prefer to restrict the term 'natural kind' to referring to biological species, which I will not discuss in this paper. I will use the term 'substance' to refer to the referents of mass terms. Mass terms 
include 'gold', and 'water', but also 'sand', 'air', 'mud' and 'blood'. Later on I will draw further distinctions.

To keep the amount of scientific knowledge reported in this paper within limits, I shall restrict myself almost exclusively to a discussion of statement (1), that is 'water is $\mathrm{H}_{2} \mathrm{O}$ ', and $\mathrm{I}$ will have reason to contrast the status of (1) with the status of statements like ${ }^{4}$

(2)a. water has minimum density at $3.98^{\circ} \mathrm{C}$,

(2)b. water boils at $100^{\circ} \mathrm{C}$,

(2)c. water has an index of refraction of 1.33299 ,

and other similar statements informing us about the electric conductivity of ice, the viscosity of water, the magnetic susceptibility of steam, and so on. Putnam has argued $^{5}$ that the reference of the first term in (1), i.e., 'water', is fixed in such a way that Oscar $_{E}$ and Oscar $_{\mathrm{TE}}$ may be in the same psychological state in 1750 with respect to the sense or stereotype of the term 'water', whereas Oscar $_{E}$ is living on Earth where (1) is the case and Oscar ${ }_{\mathrm{TE}}$ is living on Twin Earth where water is $\mathrm{XYZ}$

is the case. I shall use the term 'stereotype' in the sense that it is trivial that Oscar $_{E}$, Oscar ${ }_{\text {TE, and Harald, have the same stereotype of water. }}{ }^{6}$ I have added Harald, who, in 1066, presumably was not in exactly the same psychological state as the Oscars, but his stereotype of water is, nevertheless, roughly the same. ${ }^{7}$

With respect to (1), it has been argued by Kripke that, if (1) is true, then (1) is necessarily true. If (1) is true, it is true in all possible worlds, although, if (1) is true, this is so a posteriori. I shall use the terms 'necessary' and 'a posteriori' only in this sense. ${ }^{8}$ In the course of the discussion of this subject in the literature, this has been elucidated by stating that in discovering that (1) is the case, "physics" has discovered the essence or nature of what it is to be water, by establishing the fundamental structure or the underlying trait of water, which gives the ultimate explanation. ${ }^{9}$ I shall assume that all the underlined phrases refer to the same sort of thing or at least the same category of things.

The amount of literature on this subject is already very vast and I have extracted the following three problems for discussion with respect to the status of $(1):^{10}$ 
(a) If (1) is true, then (1) is necessarily true: There are statements which are both a posteriori and necessary.

(b) (1) states an essential property of water: "Science" discovers essences.

(c) $\quad \mathrm{H}_{2} \mathrm{O}$ and $\mathrm{XYZ}$ are two different things, but they may have the same (actually known) properties: Sense does not determine reference.

Other philosophical problems can be generated from contemplating (1), but I will concentrate on these three. At the outset I would like to stress that the three problems given above have to be answered separately: Although these sort of questions may be interrelated, it is not so that the answers have a necessary relation.

In discussing these matters, it is philosophically relevant, in my opinion, whether (1) is in fact true and what the meaning is of the terms occurring in (1). For example, most philosophers will argue (at least that is my experience) that the question whether (1) is in fact true in the actual world, is completely separate from the question whether, if true, then is it necessarily true? ${ }^{11}$ However, the philosophical discussion is full of phrases such as "dubbing events", "rule according to which the reference is fixed", "tests known by experts", "what ordinary people mean by "water"," "science has shown ...", and so on. If the meaning of all these phrases is ambiguous - if it is left open completely what in fact the rules, tests, and things shown by scientists are, then it is unclear to me what the function of such phrases is in explaining or arguing for a particular philosophical opinion. Certainly, it would not do after twenty years of philosophical investigations, having travelled to Twin Earth and back, to have to conclude that the examples chosen to illustrate the philosophical argument were unsatisfactory.

Similarly, if different logical representations of (1) are compared, for example: ${ }^{12}$
(4)a.
$\square(x)\left(\right.$ Water $\left.(x) \supset \mathrm{H}_{2} \mathrm{O}(x)\right)$,
(4)b.
$(x)\left[\right.$ Water $(x) \supset \square\left\{\left(\right.\right.$ Exists $\left.\left.(x) \supset \mathrm{H}_{2} \mathrm{O}(x)\right\}\right]$,
(4)c.
$\square\left[(\exists x)\left\{\right.\right.$ Water $\left.(x) \cdot \mathrm{H}_{2} \mathrm{O}(x)\right\} \supset(x)\left\{\right.$ Water $\left.\left.(x) \supset \mathrm{H}_{2} \mathrm{O}(x)\right\}\right]$,
(4)d.
$(x)(y)\left[\left\{\right.\right.$ Water $\left.\left.(x) \cdot \mathrm{H}_{2} \mathrm{O}(x)\right\} \supset(\mathrm{F})\{\mathrm{F}(x) \equiv \mathrm{F}(y)\}\right]$,

it is useful to know whether the extension of water includes ice, a layer 
of blue water, an isolated $\mathrm{H}_{2} \mathrm{O}$ molecule, and so on; and whether " $\mathrm{H}_{2} \mathrm{O}$ " means "composed of two volumes of hydrogen and one volume of oxygen when subjected to electrolysis", or "two atoms of hydrogen and one atom of oxygen in a particular spacial relation", or what. If this is not spelled out (or obvious from the context how to be spelled out), the discussion is not about substances, but an exercise in pure logic. It is not sufficient to say that (1) is a theoretical identity statement involving natural kinds, because nothing follows from this as to what sort of a posteriori statement (1) is. It is one thing to discuss the difference between $a=a$ and $a=b$. It is a completely different question whether (1), "Hesperus is Phosphorus", and "this stick in Paris is one meter long", are or are not substitution examples of $a=b$ in one sense or another of the identity stated. In my view, the actual meaning of the statemen's used as examples is the more important because in arguing what utstances are and whether substances have their fundamental structure ssentially often a Cartesian-type intuition is invoked.

Some philosophers would seem to agree that scientific knowledge helps us, if not to settle, then at least to explain philosophical positions. In explaining Kripke's position, Putnam writes ${ }^{13}$

It is 'metaphysically necessary' (true in all possible worlds) that water is $\mathrm{H}_{2} \mathrm{O}$; but this 'metaphysical necessity' is explained by mundane chemistry and mundane facts about speakers' intentions to refer.

I think, in order to judge, as philosophers, whether we would agree with (5), we should have a reasonable understanding, not only of the meaning of "metaphysically necessary", but also of the "mundane chemistry" and the "mundane facts" referred to in (5).

Mundane facts about water fall apart in, on the one hand, the common sense knowledge about water - this is what is called the stereotype by Putnam - and, on the other hand, the "tests known by experts". The stereotype basically gives secondary qualities, and it is usually specified by saying that water is a colourless, transparent, tasteless, thirst-quenching liquid. What the extension is of such a stereotype seems to me very vague indeed. Apparently ice is not water, a thick layer of (pure) water is not water (because it is blue), whereas fluoridised drinking water is water. ${ }^{14}$ Since at least the time of Aristotle, educated common sense knowledge about water (in the 
Western Culture, but, I would speculate, in many other cultures as well) has included: ${ }^{15}$

- water can exist in more than one state of aggregation (solid, liquid, vapour);

- water can be more or less pure;

- water has more "stable" properties than you can think of. $^{16}$

Putnam has pointed out that what he calls the stereotype is by no means supposed to include everything the speaker knows about a substance: If an average speaker were asked to produce a sample of something that is stereotypically water he would not exhibit a block of ice, although he may know perfectly well that ice is a form of water. How to delineate the stereotype, Putnam thinks, is of some psychological interest, and of some interest to linguistics, but it has nothing to do with the questions about necessity or how reference is fixed. ${ }^{17}$ However, I think, if we are advocating a causal theory of reference (as Putnam does), and probably generally so if we agree with Putnam's law of the sociolinguistic division of labour, we have to give some account of how the stereotype (which governs the colloquial use of a term) is related to the tests known by experts (which fix or define the reference). In the present case it is particularly relevant what sort of markers are part of the stereotype. Surely, if it would be the psycholinguistic habit to name all samples of water individually, without there being any trace of awareness of similarity, this would not provide a basis to relate the stereotype to tests known by experts who presuppose or confirm that all these samples consist of the same liquid. On the other hand, if it is a marker of the use of the term 'water' that it refers to a liquid (with certain specific properties) then it is part of the stereotype of being a liquid that it can boil and solidify, that it is more or less pure and that it has innumerable stable properties. And it is precisely the stereotype of a liquid that relates the stereotype of water with the tests known by experts to fix the reference of 'water' (see next section).

On the level of mundane physical chemistry, the three neglected aspects of the stereotype mentioned above are brought together when defining a substance to be pure if a phase change (= change in state of aggregation) occurs at a fixed temperature and pressure, whereas the reference of a pure substance can be fixed by means of an innumerable 
number of physical properties (examples of such reference fixing properties are given in statements (2) for water). In fact, some of these reference fixing properties may link the stereotype and the tests known by experts directly. For example, property $(2 \mathrm{~b})$, "water boils at $100^{\circ} \mathrm{C}$ ", is both a tests used by experts to fix the reference of water, and, as Wittgenstein remarked in 'On Certainty', something everybody knows to be true for certain. The fact that (2b) is not true on the top of the Mount Everest does not change a bit to the defining certainty of it. (Moreover, (2b) is also a partial definition of the centigrade scale, in which sense it might be considered as an a priori statement. These aspects are all intertwined.)

As I remarked above, I believe it only makes sense to discuss the philosophical status of (1), if we know what it means and whether or when it is true (and as I hope to show in the next section to determine the meaning is not a trivial matter). Perhaps one might argue that everybody knows what water means or is, whereas $\mathrm{H}_{2} \mathrm{O}$ means whatever scientists tell us the fundamental structure of water is. However, it is clearly not that simple if, for example, Hare argues that the view that the property of being water supervenes on the property of being $\mathrm{H}_{2} \mathrm{O}$ is false on the sole ground that this view is inconsistent with what the OED says the meanings of the term 'water' are. ${ }^{14}$ Sometimes it is added in the philosophical literature that what is meant by (1) is that the molecular structure of water is $\mathrm{H}_{2} \mathrm{O} \cdot{ }^{18}$ However, the latter phrase may mean all kinds of things (see below) and $I$ have not been able to gather from the philosophical context which meaning is intended. Perhaps the intended meaning of (1) is precisely that which makes 'water is $\mathrm{H}_{2} \mathrm{O}$ ', if true, necessarily true, but 'water is $\mathrm{H}_{2} \mathrm{O}$ ', in fact, not true. This might be further developed in showing that in fact there are no truths in science; hence scientists do not discover the fundamental structure of substances either. However, I won't attempt that and instead I will first discuss what (1) can mean and under what interpretation(s) it would be true, before entering the philosophical discussion in which (1) figures as an illustration.

\section{THE CONCEPT OF CHEMICAL SUBSTANCE}

The concept of a chemical substance as a macroscopic entity is embedded in the theory of chemical thermodynamics (which theory was founded by Gibbs at the end of the nineteenth century). If we 
want to investigate the empirical meaning of statement (1), and in particular if we want to know why water is a separate substance, the primitive concept we encounter is not substance, but the empirical concept of phase. A phase is any system which, when in a state of thermodynamic equilibrium, has constant and uniform properties throughout: a phase is a macroscopic continuum. Here 'properties' refers to properties such as density, electric conductivity, magnetic susceptibility, and so on - compare statements (2) above. A bubble of air, a piece of sugar, a drop of salt water, a fragment of glass, is a phase. A tiger, milk, and most paints are polyphasic aggregates. In principle polyphasic aggregates can be separated into different phases by mechanical means. For example many paints left to themselves long enough will separate into a solid phase and a liquid phase on top. This would not happen if it had been one phase at the beginning. The fact that often it is very difficult to separate the polyphasic aggregates (and sometimes we mistakenly take a polyphasic aggregate for a phase) does not make the empirical concept of phase less precise.

A system consisting of one phase can be subjected to a phase change by physical means such as changing the temperature, for example, melting glass, distilling sea water. If during the phase change, the properties of the two co-existing phases change continuously, the system is a solution. This can be observed when distilling sea water or when a bottle of coca-cola is put into a freezer. If, on the other hand, the properties of the two co-existing phases remain invariant during the phase change, the system is called hylotropic. If it is hylotropic over a limited range of pressure and temperature, it is a pure chemical substance. If it is hylotropic at all pressures and temperatures except the most extreme ones, it is a chemical element.

"Phase", "substance", and "element" as defined above are empirical macroscopic notions. With substance and element correspond the theoretical notions of molecule and atom (based on an atomistic model of matter) ${ }^{20}$ Historically, the concepts of "substance" and "element" were developed while "interacting" with the notions of molecule and atom. However, this is a contingent fact. If everything we know about molecules, atoms, and the whole of corpuscular physics and quantum mechanics would turn out to be false, this would not change the observations that led to the operational definitions of chemical substance and chemical element.

In defining the concepts of phase and substance, reference was 
made to the same, different, or changing properties. Which properties are these? - not secondary qualities such as colour. Think of a large mass of pure liquid water: this is one phase and it looks blue. A small sample of this blue water will be colourless. There are also pure chemical substances which, in powdered form, can have different colours. ${ }^{21}$ The same properties that define the uniformity of a phase are the properties that have to remain constant for each of the two co-existing phases during a phase change for the system to represent a chemical substance. It is these properties, called physical constants (density, conductivity, and so on), which constitute, together with the temperatures and pressures at which phase changes occur, the object of the "tests known by experts" that identify a sample as being, for example, water, and thereby fix the reference of the term 'water'. Hence, any of the statements (2) can be used to fix the reference of water.

I suspect that if the subject of discussion is whether substances (in the sense of natural kinds, also called "stuffs") have some of their attributes necessarily or whether mass terms are rigid designators, the intention is that the philosophical arguments only refer to chemical substances or elements (such as water or gold), and not to solutions or polyphasic aggregates (such as sand, wood, air, and blood). It follows that always when the example "water is $\mathrm{H}_{2} \mathrm{O}$ " is used, what is meant by the term 'water' is that it designates a chemical substance (in the sense defined above), which has a maximum density at $3.98^{\circ} \mathrm{C}$, an index of refraction for sodium light of 1.33299 at $20^{\circ} \mathrm{C}$, and so on. Hence, a thick layer of pure blue water is water and fluoridised drinking water is not water.

Chemical substances have (macroscopic) physical properties (such as their density); they also have chemical properties (such as chemical composition and reactivity with other substances). One way to determine the composition of water is to electrolyse it. This yields one volume of oxygen to, approximately, two volumes of hydrogen. We could take "water is $\mathrm{H}_{2} \mathrm{O}$ " as short-hand for this empirical finding, but I don't think that is what philosophers have in mind if they say that (1) is necessarily true.

At this point we may want to introduce the empirical law of stoichiometry: chemical substances consist of chemical elements in fixed proportions. Two things should be noted in that connection. Firstly, from this empirical law nothing follows as to the possible 
existence of molecules and atoms. Secondly, if we change the interpretation of "water is $\mathrm{H}_{2} \mathrm{O}$ " in such a way that the gas volumes of oxygen and hydrogen not only differ by a factor of two approximately, but should differ by a factor of two exactly (according to our theoretical insights), it is still not possible to conclude that in all contexts or in all possible worlds $\mathrm{H}_{2} \mathrm{O}$ is the extension of water, because in general there is no one-to-one correlation between chemical composition and chemical substance. In fact, for all scientists know at the moment, water and $\mathrm{H}_{2} \mathrm{O}$ in the above sense do have the same extension, but in general, one particular chemical composition, say $\mathrm{C}_{4} \mathrm{H}_{10} \mathrm{O}$, may correspond to more than one chemical substance.

Let us finally consider the possibility that "water is $\mathrm{H}_{2} \mathrm{O}$ " says something about the molecular structure of water - as distinct from the chemical composition. Common sense will say that ' $\mathrm{H}_{2} \mathrm{O}$ ' designates tiny things called molecules which consist of two hydrogen and one oxygen atom. ${ }^{22}$ Then (1) means that water, or any sample of water, consists of many of these molecules, and only these. But this is simply not the case, and it is difficult to imagine a physical world in which it would be the case. Chemical substances in general have a fixed composition - there are border line cases in biochemical systems, but let us leave that for the moment. But substances rarely, if ever, have a fixed molecular structure. In ice it is not possible to identify individual $\mathrm{H}_{2} \mathrm{O}$ molecules. Liquid water contains $\mathrm{H}_{2} \mathrm{O}$ molecules, but also $\mathrm{H}_{4} \mathrm{O}_{6}$ and others. Moreover it contains ions such as $\mathrm{OH}^{-}$and $\mathrm{H}_{3} \mathrm{O}^{+}$. Not all chemical substances contain ions in the liquid phase, but then I could talk about enantiomers, homeomeres, isochemical compounds, radicals and so on, which all upset the idea of giving a simple account of molecular structure.

The conclusion to be drawn from the above account is that it is not clear at all what it is that is the case if we say that (1) is true. The only interpretation under which (1) is true would seem to be if the term 'water' refers to a pure chemical substance and $\mathrm{H}_{2} \mathrm{O}$ gives the chemical composition of water. As pointed out above, this does not entail that water consists of molecules, or, for that matter, has a particular fundamental structure. One thing is clear on the above account. Because chemical substances have been defined by their physical properties, isotopes (for example heavy water, deuterium oxide) form by definition different chemical substances, although their chemical (but not their physical) properties are the same. This settles automa- 
tically all disputes as to whether isotopes present a problem to an essentialist theory of substances. ${ }^{23}$

\section{ARE MOLECULAR STRUCTURES ESSENTIAL PROPERTIES?}

What to do if (1) is not true, or only approximately true. There seem to be two ways out:

- to modify (1) such that a true statement is obtained;

- to drop (1) altogether and to investigate whether statements like (2) or any other statements can tell us what it is to be the natural kind water.

Putnam chooses the first alternative; (1) is to be replaced by ${ }^{24}$

(6) water is the quantum mechanical super-position of $\mathrm{H}_{2} \mathrm{O}$, $\mathrm{H}_{4} \mathrm{O}_{2}, \mathrm{H}_{6} \mathrm{O}_{3}, \ldots$ plus $\mathrm{D}_{2} \mathrm{O}, \mathrm{D}_{4} \mathrm{O}_{2}, \ldots$,

because that is what we have discovered the chemical composition of water in the actual world to be (and not $\mathrm{H}_{2} \mathrm{O}$ ), or, in short

(7) the molecular structure of water is something like $\mathrm{H}_{2} \mathrm{O}$.

One consequence of this, as Putnam notes, is that ${ }^{25}$

(8) These examples suggest that the "essence" that physics discovers is better thought of as a sort of paradigm that other applications of the concept ("water", or "temperature") must resemble than as a necessary and sufficient condition good in all possible worlds.

I am not sure what to make of this. Shouldn't the criteria for resemblance to the paradigm be part of the "essence" paradigm? What is meant by (8) would seem to be the same as expressed by Weyl, when discussing the reduction of all science to quantum mechanics, as follows: ${ }^{26}$

(9) A picture of reality drawn in a few sharp lines cannot be expected to be adequate to the variety of all its shades.

Even if we accept that at best we can give an "idea" of the variety of all the shades of the essence of a substance, I hesitate to consider (6) an empirical statement (necessary and a posteriori), if what it expresses 
is only a paradigm and not an expression of all the shades of reality the term 'water' may refer to.

Putnam has pointed out that it is an empirical presupposition of his argument that we have in fact succeeded in discovering the physical structure and chemical composition of water with a very high degree of accuracy, and that this is not going to turn out to be all totally wrong. ${ }^{2 \overline{7}}$ Now I do not want to dispute that in some way or other we now know more about the empirical world than two or ten centuries ago. However, in accepting something like (6) as the embodiment of the essence of water scientists have discovered, I think those scientific statements which, if true, are necessarily true become both very abstract and very vague in their empirical or operational meaning. There seems to be little difference between (6) and saying:

(10) water is what is water according to the Schrödinger equation plus....

Eventually this might lead to the conclusion that there are no contingent statements left at all in science, but I won't pursue that line.

To explain further why I think that (6) leads us to (10) and perhaps further to

(11) the whole of science in so far as it is true is necessarily true, or

(12) science is quite some way in discovering the essence of matter,

but not to an explanation of what it is to be the substance water, I have to discuss the concept "molecular structure" as used in (7) in some more detail. At least four levels of molecular structure can be distinguished: ${ }^{28}$

(a) the topology or spatial arrangement of the atoms in the molecule;

(b) the geometry of the molecule, i.e., prevailing distances and angles;

(c) the organization of the electrons in a molecule (the nature of the "bonds" between the atoms);

(d) the quantum mechanical description of nucleus plus electrons. 
Although chemical text books still tend to emphasize the visual aspects of molecular structure, the awareness that much more fluid relationships were involved grew over the century. The first serious trouble maker was the benzene molecule, for which it appeared impossible to specify exactly where there are single and where there are double bonds - the "real" situation being a kind of mixture. These so called resonance structures presented a problem for the materialistic philosophy in Eastern Europe, because statements about observable material properties can be derived from the assumption of resonance structures, although the latter do not "really" exist. I think this problem of the material base has also to be accounted for by a realist theory of natural kinds. In Eastern Europe only with difficulty the resonance concept was accepted as a purely instrumental one:29

(13) We see that resonance is a man-made concept in a more fundamental sense than most other physical theories. It does not correspond to any intrinsic property of the molecule itself, but instead it is only a mathematical device, deliberately inverted by the physicist or chemist for his own convenience.

What is left of the concept of molecular structure with the advent of quantum chemistry is an even more dubious matter. One publication by a physicist concludes: ${ }^{30}$

(14) it is wrong to regard molecular structure as an intrinsic property of a molecule,

and it is noted that approximation methods are used in quantum chemistry which are conventional but motivated by "a powerful "felt need' to make contact with the classical idea of molecular structure", which is of course not a primitive term in quantum mechanics.

Presented with the question how to relate (classical) chemistry to quantum mechanics, various opinions are possible: ${ }^{31}$

(a) Quantum mechanics is the true theory of nature (or: it is the ontology for natural phenomena). Concepts such as "molecular structure" may be of didactic value; they may be of instrumental use in making predictions that are not as yet possible on the basis of first principles - but not more than that. 
(b) Quantum mechanics is to chemistry, what statistics is to economics. It is an abstract system, chemically not interpreted, like mathematics is for physics.

(c) Quantum chemistry is on the same ground as any other theory: this is the pragmatic view. In some cases quantum chemistry is of use to gain knowledge and understanding. In other cases the theory of electrovalences is of more use. There is no need for a priori assumptions about what is more fundamental.

(d) Quantum mechanics is a useful instrument, waiting to be interpreted with reference to the "underlying" matter it is about, using a theory about hidden variables or hidden monads, the permutations and combinations of which constitute the fundamental or essential building blocks of substances.

I don't want to argue for or against any of these or other interpretations of quantum chemistry, because this is a discussion within the philosophy of science or the foundations of physics and chemistry. What is important is that the outcome of that discussion cannot be stipulated by a philosophical theory about substances or natural kinds. The same applies to the question as to whether matter is infinitely divisible. $^{32}$

Because it turns out that no clear meaning, if any, can be given to the notion of molecular structure, it is not possible to specify what the reference and essence of water is in terms of its molecular structure. If (1) is to be replaced by (6) and (6) is to be replaced by an even better statement of what water is, I think this is not about the substance water anymore, but about the whole subject matter of science. If the philosopher is impressed by the essences or other things scientists have discovered, this may be a stimulus to argue for (11) or (12), but this does not explain anything about what it means to be the same substance.

\section{THE "INTUITIVE" NOTION OF SUBSTANCE}

The second approach, when confronted with the fact that (1), "water is $\mathrm{H}_{2} \mathrm{O}$ ", is not true, is to drop (1) altogether, and to continue the discussion about the reference of water and whether there are neces- 
sary a posteriori statements with respect to facts of science such as listed under (2): water boils at $100^{\circ} \mathrm{C}$, and so on. Such statements are, beyond doubt, a posteriori: the truth of them is established (and refined) by science; they are used to fix the reference of a substance and give operational meaning to relations such as "being the same liquid as". Furthermore, they exemplify the a priori assumption that two samples of the same substance will behave in the same way in the same circumstances. Finally, they are proper cases of stable generalizations.

There is, however, one major drawback in choosing this line. There is no trace left of the "intuitive" idea that we should discover the "objective essence", the "fundamental structure", or the "underlying trait" that yields the "ultimate explanation". Nevertheless, although the so called intuitive explanatory power of (2) is much less than that of (1) - in particular because we expect (2) to be explained in terms of (1) - the arguments about necessity, rigid designators, and reference can be made as well with reference to (2). If on Twin Earth (3), 'water is XYZ', instead of (1) would be true, then, as Putnam concludes water is not really water on Twin Earth, but he also notes that XYZ would have a different boiling point, which can be construed as saying that $(2 b)$ is as necessary as (1). ${ }^{33}$

I will come back to the question of reference, if this approach is chosen, after I have said a little bit more about the concept of natural kind per se. If I state that we better first be clear about the metaphysical and epistemological status of statements (2), before considering ambiguous statements such as (1), the usual reply is that "there is an intuitive notion of substance according to which, to be of the same substance is to behave the same way in the same circumstances. Furthermore, it is part of this intuitive idea that the phenomenon of same behaviour is explicable".34 I agree that we want an explanation of the "being the same liquid as" relation. However, I think that if we wish to use an explanation of the similarity relation to illuminate mastery of natural kind expressions, there is no need to resort to "structural" properties of matter. The similarity relation that holds between samples of a particular type of matter can be explained in terms of certain properties of matter such as density. A type of matter is invariant with respect to such properties if in the same thermodynamic state. As I explained in section 2:

a type of matter may occur in gaseous, liquid, and one or 
more solid "states of aggregation", the change of one state of aggregation to another always occurs at one particular temperature and pressure.

This definition of types of matter is formulated in the terminology of current physical chemistry, but I would like to suggest that the essence of what (15) means is familiar to craftsmen and "philosophers" in many cultures over many centuries. In order to understand what "natural kinds of matter" are, there is no need for a "structural" theory of matter. The theory may change, but the melting point of gold will always remain higher than that of lead.

The argument against this, as expressed for example by Campbell in a recent paper, is of course that it does not go to the heart of understanding natural kind terms; it does not seem sufficiently to illuminate the point of these concepts. Campbell compares "gold" and "mud" in order to argue, for example against Mellor, that it is not the case that being gold is just a matter of possessing certain observational properties (as, presumably, is the case for mud). What craftsmen and alchemists were doing, he argues, when they were developing better tests for identifying gold, but not for identifying mud, was that they were working with a conception of gold that transcended mere joint satisfaction of a number of observational properties; they were guided by the conception of "explanatory structural property".

I think however that this sort of historical evidence is putting too much emphasis on the unsupported assumption that people have always been looking for the molecular structure of matter. Perhaps the interest in gold simply indicates that gold was a very precious commodity and not that there was a hunch that gold consisted of one type of atom. What was a motivating factor, in my opinion, was that both craftsmen and alchemists were busy purifying matter. Because this art was first developed for metals, we can now say, with hindsight, that this was the first area where "pure chemical kinds" were studied. Further, there was more interest in gold than in iron, not only because gold was more rare, but because the properties of gold with respect to time and place were more constant. (For example, iron rusts.) But having more constant or longer lasting properties is not a reason for being a better or a purer chemical or natural kind.

What are the criteria for establishing whether a term is used as a "kind expression"? If we look at cultures before the rise of modern science, employing words (when translated into English) such as: 
water, blood, sand, wood, air, gold, jade - what else are these than natural kind expressions to name different types of matter. ${ }^{35}$ There are such terms for everything that has been worth distinguishing. ${ }^{36}$ Only after that comes the question whether empirical investigation supports this intuition of common class membership. There is no a priori reason to call 'water' (referring to $\mathrm{H}_{2} \mathrm{O}$ ) a proper natural kind term designating a substance, and not 'blood' (because, according to our present standards, it is an odd mixture of variable composition). It is not altogether clear to me from the literature, whether the philosophical arguments about the status of natural kinds, only refer to pure substances, such as water and gold, or also to sand or blood. I guess most writers would answer: Only pure substances! However, it seems to me that it makes as much sense to say that science discovers the fundamental or structural properties of blood as to say this of water. Perhaps in the case of explaining of what it is to be blood we are more easily led to go for (partly) teleological explanations, but there does not seem to be anything wrong with that in principle.

Consider the following analogies between water and blood. Water quenches thirst and boils at $100^{\circ} \mathrm{C}$. Are such properties of water convincingly explained by invoking statement (6) [water is the quantum mechanical superposition etc.]? If so, surely the properties of blood are also explained by its being the quantum mechanical superposition of ... - just fill in anything the scientist tells you it is, and the same applies to nylon and plywood. But you might say, blood is like mud; it is just an odd mixture without underlying structure. ${ }^{37}$ For example bloods from different people may coagulate when brought together, so there is no sameness relation. But what about coca cola then? Here a sameness relation applies universally from Aquapulco to Zaria. Bloods can be separated into "purer" kinds. These purer kinds of blood, as well as coca cola, can be shown to contain different components (after all, they are both contaminated water). But in a way, the same reasoning applies to the components and to water. Water can be separated into $\mathrm{H}_{2} \mathrm{O}$ and $\mathrm{D}_{2} \mathrm{O}$. We can separate $\mathrm{H}_{2} \mathrm{O}$ into oxygen and hydrogen. We can separate oxygen into smaller molecules. Or simply take a sample of blood and a sample of water to the centre of the sun and see what happens. The only reason water is in an intermediate category of what is called a pure chemical substance, is because of the scientific discovery and definition of such substances in 
terms of their invariant melting and boiling points and similar macroscopic properties. What matter is "ultimately made of" is certainly an important heuristic for science, but it does not explain the particular sameness relation that applies to substances such as gold and water and not to natural kinds such as sand, air, and blood.

Apart from the negative argument against this to the effect that sameness of temperature and pressure at a phase change does not explain anything, also a positive reason that the structural properties are fundamental has been put forward. It is that "grasping the similarity relation is just the Periodic Law, that the chemical properties of an element are a periodic function of its atomic number. For this suggests that we can explain the chemical properties of an element by appeal to its atomic number". Although it is no doubt true that the Periodic Law explains a lot, it is not clear in what sense it would contain so to say the essence of every substance, where essences explain why the same stuff behaves the same way in the same circumstances. Firstly, although the atomic number of gold may go a long 'way to explain the chemical properties of gold, this is not obvious in the case of say oxygen, which normally occurs as a molecule consisting of two oxygen atoms. It becomes even more complicated if the same set of atoms can combine into different molecules. Secondly, in so far as the atomic number explains something, it explains something about the chemical properties which depend primarily on the outer shells of electrons. But it does not tell us anything about such simple properties as the density or the atomic weight, which also depend on the constituents of the nucleus, let alone that the Periodic Law can explain which elements are radioactive or suitable to extract nuclear energy from. If we really want to ask for an explanation in terms of fundamental structure, the only thing we can do is to present the whole of science, which brings us back again to statement (12), 'science is quite some way in discovering the essence of matter', and not to an explanation of what it is to be a particular kind of matter.

\section{THE REFERENCE OF 'WATER'}

I now come back to the question: What fixes the reference of water? According to Putnam, (1), or better (6), serves to determine what is and is not to count as water in a way facts like (2) do not. The reason 
for this is that on Twin Earth or in Oxbridge we might find a liquid

- which fits the stereotype of water;

- which fits (2), for example it boils at $100^{\circ} \mathrm{C}$;

- but which does not fit (6); it is not something like $\mathrm{H}_{2} \mathrm{O}$.

I think, however, that if we only consider physically possible worlds, it is not possible to find a liquid with a different chemical composition (or different molecular structure) then water, which fitted all the tests known by experts to fix the reference of water. If we would consider all logically possible worlds, we can consider worlds in which the laws of physics are different. But, even if the laws of physics are assumed to be only a tiny little bit different, I find it difficult to talk (in our world) about what is true or what is the case in the other world. It is certainly possible to stipulate another possible world in which there is a liquid which fits the stereotype of water and which boils at exactly $100^{\circ} \mathrm{C}$. But, there would be some properties of the sort exemplified by (2), which would be different from those of water. Hence, it would not be water, either in a macroscopic or in a microscopic sense.

I think scientific investigations has led to the conclusion that:

$$
\text { water is } \mathrm{H}_{2} \mathrm{O} \text { iff water has a boiling point of } 100^{\circ} \mathrm{C} \text {. }
$$

This is an equivalence, not an implication. In other possible worlds, in which the laws of physics are different, both (1) and (2), or one of these, may not be true. In that sense neither (1), nor (2) is necessary. (If the statement is not true, of course it is not necessarily true either.) However, there would not be any water in these worlds. In any possible world, either there is water, or there is no water. If there is water, it boils at $100^{\circ} \mathrm{C}$ and has a molecular structure, which is abbreviated as $\mathrm{H}_{2} \mathrm{O}$ - this is what scientists tell us, hence is revisable. What is water depends on the characteristics of the stuff around here. If on Twin Earth or somewhere else we come across XYZ, there are two possibilities:

(a) If some of the outward properties of $\mathrm{XYZ}$ are different from those of $\mathrm{H}_{2} \mathrm{O}, \mathrm{XYZ}$ is not $\mathrm{H}_{2} \mathrm{O}$. Lots of liquids on first view look like water, but turn out not to be water. Perhaps some very clever imposters are possible, which we have not discovered as yet. But there is no philosophical problem in this case. 
(b) If all known observable properties of $\mathrm{XYZ}$ and $\mathrm{H}_{2} \mathrm{O}$ are the same, how are we to find out whether it is $\mathrm{H}_{2} \mathrm{O}$ or $\mathrm{XYZ}$. We observe that water freezes when it gets colder. Surely this is an "outward property" of water. Given the way scientific knowledge about chemical kinds has developed "having the same molecular structure" is equivalent to saying "has the same (outward and other) properties". The same chemical kind may display different secondary qualities. But I know of no examples, where compounds of different molecular structure share all their outward properties.

Assume $\mathrm{XYZ}$ and $\mathrm{H}_{2} \mathrm{O}$ share many properties, in particular what is called the stereotype, but when electrolysed $X Y Z$ does not yield two volumes of hydrogen to one volume of oxygen. Then $\mathrm{XYZ}$ obviously is not water. Perhaps we have an interesting scientific problem, but not a philosophical problem. If all properties we know of are the same, it is extremely speculative to say that some water is $\mathrm{XYZ}$ instead of $\mathrm{H}_{2} \mathrm{O}$. We might as well say: on Twin Earth there is stuff that looks like water, but it does not have a molecular structure - which is a meaningless statement unless some sort of empirical support is provided for this statement. On the other hand, if we have determined that some water is $\mathrm{XYZ}, \mathrm{XYZ}$ displayed certain observational characteristics, which it does not share with water.

Against this it might be argued that there is a demonstrative element in the fixing of the extension of 'water', precisely because what is in question is not whether $\mathrm{XYZ}$ and $\mathrm{H}_{2} \mathrm{O}$ have all their properties in common. The properties we know of do not suffice to fix the reference, because they are the same for $\mathrm{XYZ}$ and $\mathrm{H}_{2} \mathrm{O}$, but: "It may be that further tests, which we have not yet carried out, would indeed reveal differences at the macroscopic level between the two molecular structures." ${ }^{38}$ But if so construed, it may well be that the fundamental structure of water is different in London and Moscow and we may never find out which outward properties are different. Either we know that the molecular structure is different and then there are also outward properties which are different (determining that something is $\mathrm{XYZ}$ involves observation of outward properties), or we speculate that the structures are different (we determine it to be $\mathrm{H}_{2} \mathrm{O}$ in both cases, but this can be wrong), in which case we take away any ground for there being substances at all. 
Part of the problem is that if a statement is made such as

the matter which is local relative to our community is relatively constant in composition,

it is very difficult to assess the meaning of (17), because of the vagueness of the terms 'matter' and 'composition'. If we take (17) at face value, perhaps it can be expanded as follows:

(18) the matter which is local relative to our community can be distinguished in solids, liquids, gases and mixtures of these,

(19) the different types of matter can be distinguished further by their colour, density, and so on,

(20) it is possible to name different types of matter because they have properties that are relatively constant with respect to time and place,

(21) the best (but not the only) examples of types of matter with constant properties are chemical kinds,

(22) an important (but not the only) parameter that partly determines the properties of types of matter is the chemical composition,

(23) eventually everything about natural kinds is to be explained in terms of quantum mechanics.

What I have been trying to explain is that "the stability in our use of token-reflexive natural-kind expressions" is explained by the truth of (18)-(20). The rest is only a further theoretical explanation. Whether we prefer a full-blown realistic or a full-blown instrumentalist account of scientific theories (or something in between), this is a separate question from explaining that there are substances in terms of (18)(20). Also, all our views about the structure of matter might change and still (18)-(20) would hold. ${ }^{39}$

My conclusion is therefore that the stability in our use of natural kind terms depends entirely upon macroscopic properties and regularities such as the ones expressed in statements (18)-(20). ${ }^{40}$ Campbell has pointed out to me that if (18)-(20) hold for water, it might still be the case that the underlying structure flickered through being $\mathrm{H}_{2} \mathrm{O}$ one minute, $\mathrm{XYZ}$ the next, something else after that, and on again unpredictably. I think this speculation can only be empirically meaningful in two ways. Either there is a scientific explanation such that the same natural kind, on a micro level, flickers through 
various molecular or other microstructures - similar to the resonance structures referred to above. Or, $\mathrm{H}_{2} \mathrm{O}, \mathrm{XYZ}$, and so on really represent different things, in which case there will be macroscopic properties that change from moment to moment (for example the meter readings that tell us about the flickering).

Experts fix the reference of 'water' by using defining properties such as water boils at $100^{\circ} \mathrm{C}$. If these and (18)-(20) are true, then the experts fix the reference necessarily; (2), if true, is necessarily true. If somewhere else we find XYZ, which superficially resembles water, then we don't follow the broadly Fregean conclusion that water refers to either $\mathrm{H}_{2} \mathrm{O}$ or XYZ. XYZ is something different than $\mathrm{H}_{2} \mathrm{O}$ and experts will tell us how to fix the reference of $\mathrm{XYZ}$ and what the difference is. ${ }^{41}$

\section{POSSIBLE WORLDS AND POSSIBLE CONTEXTS}

Both 'water' and 'liquid having a melting point of $0^{\circ} \mathrm{C}$ ' are projectible postulates, ${ }^{42}$ because being the liquid water and being the liquid having a melting point of $0^{\circ} \mathrm{C}$ is the same thing according to the scientific theory of substances. This scientific conclusion, as well as any other conclusions with respect to "statement (2) type" properties of water, applies anywhere in the universe, not only locally. However, what we have studied locally may have been studied under boundary conditions, which do not apply everywhere in the universe. Scientists aim at being aware of all relevant boundary conditions, but it is always possible that they have overlooked one.

Water is what bears a similarity relation to local matter - let us accept that. However, what we have studied locally may have been studied under boundary conditions that do not apply everywhere. "Elsewhere" the boundary conditions may be different from "here". Most people can boil an egg in local water, but not all. This has something to do with the local boundary conditions, not with water being this or that. The scientist establishing the relative weight of water and hydrogen not only assumed that his colleague would find the same answer, but also that the same answer would apply to water and hydrogen anywhere in the universe. It is clear from the development of physics and astronomy that this has always been assumed. For example, the existence of radioactive substances was hardly discovered when the age of meteorites was compared with that of the earth on the basis of measurements of the relative concentrations of 
radioactive elements in the meteorite assuming a universal theory about the decay of the heavy elements in the universe - although, in fact, the theory itself (which explains the instability of radioactive atoms) was not known at that time.

What is the case (here and in other possible worlds) not only depends on the theories we have, but also on the parts of the world we are considering and the particular boundary conditions there. Putnam, and many others, have argued that there is no such thing as "necessary condition for membership in the extension of the term"; for example, that fish breathe through gills is not such a necessary condition for being a fish. ${ }^{43}$ Assume, for the sake of the argument, that there are such necessary conditions. How would we find out about them? If we discover the necessary condition, of course we are fallible. So the only thing we might say is:

(24) if it is true that all fish breathe through gills then this is a necessary condition for class-membership.

Assume we believe that it is true that all fish breathe through gills, how are we going to distinguish between different types of necessities? We may always find out in the future that it is not true that all fish breathe through gills, and if we do, breathing through gills is not a necessary condition. ${ }^{44}$ Similarly,

(25) if it is true that an electron has, at any time, both a place and a momentum, then this is a necessary condition for being an electron,

but if we find out that it is not true, then it is not a necessary condition. What we would consider a necessary condition, depends on what we know about the thing. Because of what we know about lemons and tigers, 'being yellow', or 'having stripes', would not qualify as terms referring to necessary conditions for being a lemon, or a tiger, respectively. Being a necessary condition only makes sense relative to a theory. If there are trans-theoretical terms (because the world, for the greater part, contains the same things), then, because there are the same things out there, they have some necessary characteristics. Whatever we propose as necessary characteristics may not strictly fit the things out there and what we propose as necessary characteristics may continuously change, but it still corresponds so to say to the 
necessary characteristics of the things out there. ${ }^{45}$ Consider: there is no temperature below zero degrees on the Kelvin scale.

This has been called the zeroth law of thermodynamics. Somebody in 1930 would say that if we try to imagine a possible world in which there are temperatures below absolute zero, this is very difficult because some of the most fundamental physical laws would have to be different. ${ }^{46}$ Certainly it would not be another physically possible world and there would be no trans-world causal relation to our world: in that other world our term 'temperature' would have no reference. However, by 1984, the concept of temperature has been enriched so far that it is not true anymore that there are no temperatures below zero degrees Kelvin. ${ }^{47}$ This is only so for certain physical systems. However, no doubt it will be possible to give a theoretically very sophisticated rephrasing of (26), stating a new necessary condition, of which the original (26) is some sort of simplification for certain cases. This example illustrates that the distinction between what is a different possible world and what is a different context, depends on our knowledge about the contexts we have actually investigated. I think we are in a similar situation if we consider the possibility whether water is perhaps not always $\mathrm{H}_{2} \mathrm{O}$, but for example XYZ.

Although the term 'context' certainly recurs in philosophical publications, I think the multitude of levels of this notion would warrant much more attention in the philosophy of meaning, language, and science. Let me try to bring this out once more by summing up how natural kind terms could be seen to refer. The reference of terms like 'water' and 'blood' is provisionally determined on the basis of our acquaintance with samples. In the course of time, experience (including that of experts) tells us whether any important distinctions have to be made (for example between 'water' being a pure substance and 'blood' a solution). Scientists also provide us with more and more refined or precise reference fixing observational characteristics. These characteristics, such as water boils at $100^{\circ} \mathrm{C}$; the half life of radium is 1400 years; or: sodium colours a flame yellow - these characteristics have a complex status:

(a) They are a posteriori in the sense that we have found out that the melting point of lead is higher than that of water. 
(b) They are necessary, because in all possible worlds where there is water, it has a minimum density at $3.98^{\circ} \mathrm{C}$.

(c) They are a priori in the sense that they define for us what to count as water and what not - they set the standard so to say, just like the standard kilogram in Paris. ${ }^{48}$

(d) Finally, they are contingent, because all physical laws might have been a tiny little bit different, in which case we would have a substance very similar to water with very similar properties.

The last aspect leads us again to the context/possible worlds distinction. If, in another world, the boiling point of what would seem to be water is $99^{\circ} \mathrm{C}$ at sea level, this would not be water, provided all boundary conditions are exactly the same as in our world. But how would we know that all boundary conditions are the same?

\section{NOTES}

* This research was made possible in part by a grant from the Netherlands Organization for the Advancement of Pure Research (Z.W.O.) to work in Oxford during the summer of 1984. I have benefited in particular from discussions on this subject with $M$. Dummett, L. J. Cohen, D. Wiggins; from contributions to the discussion after seminars I gave on the subject at the Universities of Durham and Hull in June 1984; and from correspondence with J. Campbell, G. Forbes and H. Putnam.

${ }^{1}$ See references to the publications by Kripke and Putnam in the bibliography. It should be noted that in particular Putnam's opinions have changed over time, especially with respect to the notion of realism. See on this note 10 .

${ }^{2}$ It has been pointed out to me that Kripke's view is that statement (1) is an identity statement in which two proper names are used. Because (2) involves descriptions, it is then trivial that Kripke's arguments would not apply to (2). I think however, this is just a matter of terminology. If there is some sense in Kripke's concept of rigid designator, then it depends on the context (in our world) in which an expression is used whether it is meant to be a rigid designator. Whether the expression concerned looks like a proper name or a description is irrelevant. See also Davies and Humberstone (1980), who suggest to read (1) as an a posteriori true identity between two entities denoted by descriptions. If it were the case that Kripke is only interested in the necessity of a logical identity, then we should forget about everything he says about natural kinds or other things that exist in this world. In that case the discussion is only about statements such as ' $a=a$ ' and ' $a=b$ '. However, if we want to consider substitution examples of ' $a=b$ ', then we should first consider the meaning of such alleged substitution examples, before we can judge whether it is a proper substitution example of ' $a=b$ ' in the sense of logical identity analysed by Kripke.

3 These points are further discussed below. See in particular section 3 . 
4 For simplicity all statements are in an elliptic form: all statements refer to liquid water at atmospheric pressure. In statement $(2 \mathrm{c})$ also the temperature and the type of light is missing. It is a characteristic of this class of statements that they specify the value of a physical quantity, thus characterizing the substance. If the statement itself does not already include a value of the temperature and/or the pressure, the quantities specified in the statement will always be a function of the pressure and the temperature.

5 See Putnam (1975, pp. 215-271).

6 I follow Putnam in taking the stereotype to be a rather loose part of the meaning; in particular not everything that is contained in the stereotype needs to be true. Because the stereotype need not be true of a referent, it is not a sense or the specification of a sense (Farrell, 1983). However, I include everything in the stereotype that is considered of importance in daily communication when using the term (see main text below). See on the relation of Putnam's stereotype to Kaplan's character Almog (1981a) and on the relation to Frege's terminology Wiggins (1980, p. 79) and Salmon (1982, pp. 12, 153). 7 See on Harald, Hare (1984), who considers the fact that in 1066 Harald did not mean $\mathrm{H}_{2} \mathrm{O}$, when using the term 'water', an argument against the view that being water is a supervenient property. However, Harald might well have believed that water is one of the four or five elements of which all bodies are composed, and this would be sufficient, on Hare's own terms, that being water is a supervenient property. Of course it is so that on the basis of current knowledge, we assume that the molecular structure of the North Sea in 1066 was primarily something like $\mathrm{H}_{2} \mathrm{O}$. Of course it is so that Harald did not know that. But nothing particularly interesting follows from just that (either for Putnam, or for Hare).

8 See Kripke (1980, pp. 38, 116-119, 123-128, 138).

9 For example Kripke (1972, p. 330) writes: "In general, science attempts, by investigating basic structural traits, to find the nature, and thus the essence (in the philosophical sense), of the kind".

${ }^{10}$ Points (a) and (b) have been argued for primarily by Kripke; points (b) and (c) primarily by Putnam. See Kripke $(1972,1980)$ and Putnam (1975, pp. 215-271, 1977). Since then Putnam has changed his position with respect to "metaphysical realism". See Putnam $(1978,1981)$ and the Preface in his (1982). This means, roughly, that he does not support (a) anymore; his position with respect to (b) is modified (and will be discussed below), but he still upholds (c). For example, in Putnam (1983), instead of $\mathrm{XYZ}$ on Twin Earth, what is called water there is now $50 \% \mathrm{H}_{2} \mathrm{O}$ and $50 \%$ grook. (This mixture, it is stipulated, will pass all the lay tests for water.) No reference is made to their being essential properties; there are even no references to microstructures (instead of "molecular structure" only "chemical formula" is used). But it is still the case that: "the reference is partly fixed by the substance itself (through the use of examples). The word 'water' has a different extension on earth and on Twin Earth because the stuff is different not because the brains or minds of Twin Earth speakers are in a different state than the brains or minds of earth English speakers in any psychologically significant respect". On the other Putnam's discussion of the contents of the mental representations of two Ruritanian children seems consistent with the idea, advocated by Dummett and others in defense of Frege, that the "social sense" determines the reference "since extension is fixed collectively" (Putnam, 1982, pp. 144-145). The causal theory of reference and the question as to whether we can argue from that to some form of 
essentialism has been analysed in considerable detail by Salmon (1982), who gives a full account of the contributions of Donnellan, Kaplan, Putnam, and Kripke to this development. See McGinn (1982) for a recent defense "that there can be differences of content unaccompanied by differences of use".

${ }^{11}$ For example Farrell (1983): "Let us suppose - it does not matter whether we are supposing truly or not - that water is composed of $\mathrm{H}_{2} \mathrm{O}$ molecules,..." I have received similar responses when presenting predecessors of this paper to philosophical audiences. If I say that it is relevant whether (1) is in fact true, I say that because that will tell us something about what (1) means, and what (1) actually means is relevant to its metaphysical or epistemological status - this status is not simply determined by its form and not even by some vague general classification like "theoretical identity statement". However, I do not hold that "facts" as such can swing the balance in a philosophical dispute. For example, I think Hare (1984) is wrong "in methodology" to say that the view that the property of being water supervenes on the property of being $\mathrm{H}_{2} \mathrm{O}$ seems to him "obviously false ... because the word 'water' came into use long before anybody has heard of chemical properties or natural kinds ...". Similarly, if Dummett (1973, p. 121) says with respect to the statement "Jesus Christ was born in $1 \mathrm{AD}$ " that: "This statement is certainly not necessary, since, according to the scholars, it is not even true", this fact is irrelevant as an argument against Kripke's account. However, it is certainly relevant in the process of assessing Kripke's views to investigate the meaning of such a statement including its truth conditions.

12 These examples are taken from Ackerman (1980), Forbes (1981), and elsewhere.

${ }^{13}$ Putnam (1981, p. 47). That the status of a sentence depends on what the words in the sentence are being used to denote, is brought out clearly, for example, by Daum's (1982) discussion of Schlick's realism.

${ }^{14}$ The philosophical literature on substances is very confused about the actual use of the term 'water', in particular the fact that 'water' can be used in the sense of liquid water and in the sense of " $\mathrm{H}_{2} \mathrm{O}$ ", which can occur in various states of aggregation, seems to have a very disturbing effect. If one wants to go for underlying traits that should explain what it is to be a particular natural kind, Schwartz (1980) account is obviously correct, I think: Natural kind terms occur where the same stuff or thing characteristically takes a lot of different forms. Water can occur as liquid, solid, or gas. Animals are born, develop, grow old. It is natural to assume that there is some underlying trait that makes some stuff or thing to be of the kind. It is the underlying trait that remains the same throughout these changes. Hare's (1984) view, backed up by the $O E D$, that there are two senses of water (common sense liquid water and scientific sense $\mathrm{H}_{2} \mathrm{O}$ ) is obviously incorrect. Hare says that if somebody was begging for something to drink, he would not thank you if you would direct a jet of steam at him. But surely, he would not thank you either if you directed a jet of liquid water at him, which had a temperature of $90^{\circ} \mathrm{C}$, or if you threw him in the liquid of which the sea is composed (which, according to Hare and the OED, is water in the first sense). Similarly, a person who needs butagas to cook, prefers a cylinder with "butagas-liquid" - the same cylinder containing only butagas (that is "butagas-gas") would be useless to him. I think it is generally taken for granted that dictionary definitions give a description of the "normal" case in "normal" circumstances, where it is the reference of 'normal' that is taken for granted. Of course there is a sense in which 'water' refers only to liquid water and a sense in which it refers to water which may be in the form of vapour, fog, rain, or ice; 
but, equally of course, these two senses are connected in colloquial language (see next note). As Unwin (1984) says, extending Wiggins (1980) views on substances in the sense of Aristotelian individuals to the referents of mass terms: "Thus water (meaning $\mathrm{H}_{2} \mathrm{O}$ ) is a pure mass-term, but water (meaning liquid $\mathrm{H}_{2} \mathrm{O}$ ) is not". Nevertheless, in many publications, 'water is $\mathrm{H}_{2} \mathrm{O}$ ' is considered to refer to a liquid only. For example, Putnam (1975, p. 232) says that $x$ bears the relation same ${ }_{\mathrm{L}}$ to $y$ just in case $x$ and $y$ are both liquids and $x$ and $y$ agree in important physical properties. Similarly, Putnam (1983): "what we intend to refer to when we use such a word as 'water' is whatever liquid has the same composition as...". But if there is anything physically important about this sameness relation, it is that $x$ and $y$ are both substances, which can occur in more than one state of aggregation.

${ }^{15}$ See on Aristotle's views on water his Meteorologica. For the meaning of 'water', before it was discovered that it was not an element, see for example Chambers' Dictionary, 1728, or Croker's Dictionary, 1766. Whether the prevailing theory of matter was atomistic or not, on the "stereotypical" level, there has always been an awareness of three, related, senses of 'water': pure liquid, impure liquid, substance occurring in various forms, but these differences "are not so essential, as to prevent the whole from being considered as of only one kind" (Croker's Dictionary).

${ }^{16}$ I use the term 'stable' in the sense of Schwartz (1980) when he says that a natural kind term is a subject term in a stable generalization. A stable generalization, on Schwartz's account, is necessary if true, but corrigible.

17 Putnam, personal communication. I argue below that the delineation of the stereotype is of importance to relate it properly to the tests known by experts as part of the sociolinguistic division of labour. This point, viz. the interdependence of ordinary and scientific language, is strongly supported by Putnam in his "meaning holism" (1983), and has been stressed before in particular by Dummett $(1978$, p. 427$)$ in his discussion of Putnam's conception of the division of linguistic labour: "The meaning of the word 'gold', as a word of the English language, is fully conveyed neither by a description of the criteria employed by the experts nor by a description of those used by ordinary speakers; it involves both, and a grasp of the relationship between them."

${ }_{18}$ Explicit reference to the fact that " $\mathrm{H}_{2} \mathrm{O}$ " says something about the molecular structure can be found for example in Putnam, Kripke, Ackerman. Often it is taken for granted what " $\mathrm{H}_{2} \mathrm{O}$ " might mean. Salmon (1982) uses the terms "chemical composition" and "chemical structure", apparently interchangeable. For example (p. 163): "From these three ingredients - the ostensive definition of water, the fact that the paradigm has the chemical structure $\mathrm{H}_{2} \mathrm{O}$, and the fact that consubstantiality consists in having the same chemical structure - we easily generate the necessary a posteriori truth that water is $\mathrm{H}_{2} \mathrm{O}$, or more accurately that every sample of water has the chemical composition of two parts hydrogen and one part oxygen". (Compare also pp. 81, 86, 178.) But it is not made clear whether or not it is assumed that there is some sort of structural relationship between hydrogen and oxygen.

19 The physical chemistry summarized in this section is based primarily on Timmermans (1963) and literature on the philosophy of chemistry reviewed in Van Brakel and Vermeeren (1981).

20 Traditionally, there exists an empirical concept of "molecule", generalized from the concept of substance as defined above. It is the smallest "sample" of the substance which still has the same properties. However, it is not clear what these properties are. 
Alcohol is transparent and may contain dimers, a gas has a pressure, and all substances (whatever phase they are in) have an electric conductivity; but a molecule has none of these properties. It seems therefore advisable to restrict the term 'molecule' to refer to a theoretical concept, in which the idea of structure and constituting atoms is contained. A similar problem is noted by Mellema (1981), in a discussion of the (an) identity sign in the logic of mass terms: "Water, of course, is composed of discrete molecules, but it will not do to suppose that molecules may be regarded as the discrete units over which one quantifies". Scientifically, it is not at all clear what "water is composed of discrete molecules' would mean; hence there is no urgency to derive a philosophical problem from a statement thus formulated. More complicated conceptual problems arise, if we ask what we mean by saying that water is composed of oxygen and hydrogen. (In producing oxygen and hydrogen from water, water submerges, whereas oxygen and hydrogen emerge - although they had been there all the time.) I won't pursue that here (see Paneth, 1962; Van Brakel and Vermeeren, 1981). This account of the difference between the empirical concept of substance and the theoretical concept of molecule is not to be confused with the semantic distinction between "nominal" and "predicative" mass nouns (Ter Meulen, 1981): A nominal mass noun denotes a substance, which is an abstract entity (as in "gold is an element"). A predicative mass noun takes quantifiers and various modifiers and denotes a set of quantities of the substance. An argument about whether there are rigid designators will be about nominal mass terms; but, of course, the quantities of substance are referred to contingently. (Compare also Salmon, 1982, p. 86.) This distinction is well documented with respect to physical quantities (see for example Palacios, 1964) and is basically an expression of the belief that the "concept" is fixed, but what there is changes all the time. It can, however, be applied to both the concepts of "substance" and of "molecule".

${ }^{21}$ Mercuric oxide can be obtained in red and in yellow form, the difference being caused by the size and surface structure of the powder particles. This case, the same phase displaying different colours, should be clearly distinguished from cases like diamond and graphite - the same substance being displayed in two different phases.

${ }^{22}$ It adds to the confusion that it is not always clear whether the term ' $\mathrm{H}_{2} \mathrm{O}$ ' refers to one molecule, to a set of similar molecules, to the chemical composition, or to some concept or other.

23 This point has been discussed at great length in the literature. See Zemach (1976), Mellor (1977), Platts (1983), Smith (1981), Wiggins (1980, pp. 211-212). Of course, by stipulating in a scientific theory (as summarized in the main text) that isotopes are different substances, this does not exclude the possibility that the discussion about isotopes refers to a real problem - no matter how sensible the definition of substance may seem. I think at least two problems are hidden in this discussion. Firstly, there is the question whether, if it is accepted that substances do have essential properties, how do we know that scientists have actually discovered any of these properties (see for example Averill, 1982). Secondly, there is Locke's statement (as referred to by Platts, 1983; see also Fales, 1981) that our natural kind classifications are as interestingly informative about ourselves as about the natural orders of things. If the essential properties have to have an explanatory function, wouldn't their relevance be determined by the interests of the investigators? If so, there is of course no problem with the isotopes. Sometimes atomic number is the "essential explanatory property"; at other times the isotope number is. It would not only be so that there have been radical 
changes in what scientists consider to be the essence of things (Zemach, 1976) - that might only indicate that they are making progress. It would also depend on which scientists you asked. The consequence of this would be that what are called essential properties are only so relative to our knowledge or way of looking at the world (Smith, 1981; Farrell, 1983). And if the extension a term has is relative to its use within a given linguistic community, then in 1750 the extension of 'water', as used by Oscar $_{E}$ and Oscar $_{T E}$ is the same (sense determines reference), no matter whether we say now that in fact in 1750 the molecular structure was different on earth and on twin-earth.

${ }^{24}$ Putnam (1982, p. 63). Note that on the account given in the previous section, (6) is still false. This is so because pure water is defined by its physical properties, which are different for different isotopes. Hence water, if pure, will not contain $\mathrm{D}_{2} \mathrm{O}$, whereas according to Putnam, containing some $\mathrm{D}_{2} \mathrm{O}$ is part of what it is to be water. The fact that water as it occurs on earth consists of a mixture of $\mathrm{H}_{2} \mathrm{O}, \mathrm{D}_{2} \mathrm{O}$, and some other isotope combinations of hydrogen and oxygen, is due to the history of the earth (which might well have been different). It is not, so to say, that $\mathrm{H}_{2} \mathrm{O}$ and $\mathrm{D}_{2} \mathrm{O}$ both occur in the same quantum mechanical formula, in the way that we can envisage that $\mathrm{H}_{2} \mathrm{O}$ and $\mathrm{H}_{4} \mathrm{O}_{2}$ do occur in the same formula. Therefore the substance with composition $\mathrm{H}_{2} \mathrm{O}$ is definitely different from the substance with composition $\mathrm{D}_{2} \mathrm{O}$. Of course, this does not exclude the possibility to argue for the statement that the combination of $\mathrm{H}_{2} \mathrm{O}$ and $\mathrm{D}_{2} \mathrm{O}$ (and a few other things) in a certain (or, more probably, in any) proportion constitute a natural kind as well. If the philosophical concern is primarily to "save" a statement that is both a posteriori and necessary, a solution might be to consider: "Water contains hydrogen atoms" (Tye, 1983). But as there are many things that contain hydrogen atoms, this statement is extremely uninformative about what water is.

${ }^{25}$ Putnam (1982, p. 64). See also Farrell (1983): "two samples of liquid are both samples of the same liquid if they share, or have relevantly very similar, molecular structures"; (italics added). It would also seem that it is difficult to take (6) as an identity statement in the sense of Kripke.

${ }^{26}$ Weyl (1963). The expression "a few sharp lines" refers to the lines in a valence diagram, representing the bonds between the atoms in the molecule.

${ }^{27}$ Putnam (personal communication, 1983). It is not clear to me whether there is general consensus on this point in the philosophical literature.

${ }_{28}$ Following Maccoll (1964) and adding (d). Many publications give similar classifications. As noted before philosophers are usually very vague about what sort of molecular structure they have in mind. It may be speculated that in most cases level (a) is intended. The following two quotations are explicit examples of this. "Molecules will be said to match if they contain atoms of the same elements in the same topological combinations" (Quine, 1977). "Thus 'molecule of $\mathrm{H}_{2} \mathrm{O}$ ' denotes a natural kind, membership in which depends on whether a given molecule is made up of certain kinds of atoms related in certain ways" (Hirsch, 1982, p. 266). Note that in both quotations reference is made to "kinds" (viz., "molecule", and "molecule of $\mathrm{H}_{2} \mathrm{O}$ "). These may be proper natural kinds on one view or another. But nothing follows from this, necessarily, with respects to the kinds "substance" or "water".

29 Wheland, as quoted in Kursanov et al. (1959). Although the mesomer concept is considered useful as a mathematical tool, it is still argued that: "The basic assertion of the resonance theory, that 'resonance' in some way can determine the properties of molecules, is devoid of meaning." 
30 Woolley (1978) in an article entitled "Must a molecule have a shape?".

${ }^{31}$ See Van Brakel and Vermeeren (1981) for references to publications in which the various interpretations of quantum chemistry are defended.

${ }^{32}$ Cohen $(1979$, p. 325) has argued against Quine's (1977) proposal to give a wholly extensional account of natural kinds (as a set of objects that match each other in respect of their parts like the molecules of a particular chemical element) that this proposal makes the whole analysis depend on the infinite divisibility of matter. The same objection can be made, I think, with respect to substances having their structural parts essentially, because these parts are themselves substances again.

${ }^{33}$ Putnam (personal communication, 1983). See also Putnam (1975).

${ }^{34}$ Forbes (personal communication, 1984). See also Campbell (1982) and Platts (1983) for detailed arguments to the effect that Putnam's "important physical properties" which two samples of the same substance have in common are those properties which are important for explanatory purposes.

35 As noted above I suspect that most writers on the status of statements like 'water is $\mathrm{H}_{2} \mathrm{O}$ ' only think of chemical substances as defined in section 2 , and which probably correspond with what Quine (1977) calls theoretical kinds. I don't want to go as far as Hirsch (1982, pp. 264-285) who also considers "red object" to be a natural kind. However, I will say that everything qualifies as a kind if we have a minimal sort of theory about the kind (compare Wiggins, 1980).

${ }^{36}$ What has been worth distinguishing, of course, depends on the context. Mellor (1977) argues against Putnam's essentialist theory that in case of elements high in the periodic table (and which do not occur in the world) there is no "ostensive reference, to just this archetype in this world", and therefore Putnam's theory of causal reference fails. But that is not to the point. It is only in a scienific context that there is interest in these elements, and when one scientist has produced the element in his laboratory, even if its life time is very short, that is sufficient to secure the ostensive reference to it.

${ }^{37}$ Or you might say: there is no identity of the sort 'blood is .... However, on such a strict view of identity (6) is not an identity either. As Wiggins (1980) has argued with respect to the individuation of individuals, it is sufficient if there is a sufficient amount of theory about the sortal concept.

${ }^{38}$ Campbell (personal communication, 1983).

39 The point that our views about the structure of matter might change completely has been levelled against the theories of Kripke and Putnam by several writers. For example, Averill (1982) has argued that nothing in Kripke's and Putnam's theory rules out the possibility that there are "zits", which are very small particles lurking in and around the nucleus of the atom. The basic zit structure determines all the properties of the atom, including the atomic number. Zit structure is more basic than atomic structure: it allows there to be variations on the same basic zit structure such that gold can also have atomic number 283. Because of the accidental properties of the Big Bang in this world gold with atomic number 283 does not occur. Therefore Kripke's arguments only support that: "If a feature of a substance is basic according to a scientific theory that is both true and the best, most comprehensive theory possible of substance, then this feature is an essential feature of that substance". However, neither scientists, nor we can ever find out whether the prevailing or any other scientific theory is a theory with such properties. Similarly, Smith $(1981$, p. 101): "If we gave up atomic 
theory, perhaps in favour of sub-atomic theory or of some non-corpuscular theory, then no doubt 'having atomic number $x$ ' would cease to be of central importance. Likewise, before 1750 there was nothing like the modern notion of an element, and so nothing could be said for distinguishing substances according to chemical formula." However, I think, all these speculations and historical facts can be incorporated in an essentialist theory by saying that this is all to do with what statements are true a posteriori. We can conceive (in the epistemic sense) of the falsity of a claim, which because it is believed to be true is a metaphysically necessary truth (Schwartz, 1980; Tye, 1983). The question is whether we think it makes sense to talk about the concept of such metaphysically necessary truths. Only after we have settled that can we say what it means that we can imagine that water is not $\mathrm{H}_{2} \mathrm{O}$.

40 Wiggins $(1980$, p. 82$)$ quotes Heraclitus as saying "hidden structure dominates apparent". As Wiggins pointed out to me Heraclitus meant this in the general sense, not in the sense of an "underlying" structure. Everybody who opens his eyes can reveal the hidden structure. Hence, in this case the hidden structure is revealed by (18)-(20). So I am not saying that there might be other sorts of explanatory properties than those relating to molecular structure, but equally "underlying" and "fundamental" (for example Averill's "zits" - see previous note). I mean that the stability in our use of natural kind terms depends entirely upon macroscopic properties such as those embodied in (18)-(20). The question what these "important physical properties" are, which according to Putnam determine the sameness relation (see note 34), has been raised in many publications, but it is generally assumed that they have to be microscopic properties. An exception is Dupré (1981): "some theoretically important property (generally, but not necessarily, microstructural)", but this is not further worked out. As noted in note 18, Salmon (1982) refers to chemical composition as a possible essential property, but it is not clear whether this denies any microstructural assumptions.

41 It follows from this account, based on the scientific definition of chemical substance, that artificially produced substances are the same substances as those occurring in nature (if they fulfill the criteria of being the same substance). Dummett (1978, p. 428) has suggested that Kripke's argument in particular might be strengthened by considering that it is necessary that exemplars of a kind are of common origin. Although this is mentioned in particular with reference to being a certain animal "in virtue of its membership in a breed or family", some substances are included: "I suppose then anything produced in a laboratory would be only artificial silk, and not real silk, whatever its chemical structure. But for the most part words of types of substances are not like this." Although this example certainly supports the "social character of meaning", being artificial or natural silk is not more than a socially contingent property, still assuming we are interested in the reference of mass terms and the properties of substances. Of course it is possible (i) to consider natural silk in the specific sense of being the product of a particular animal, like "hen-eggs", in which case it being a "kind" would be derivative of being an animal of a certain kind, or (ii) to consider silk in the specific sense of the material from which first threads and then woven materials are made, in which case some of its (relative to being a substance) superficial properties might be "essential" properties relative to being worked into an artifactual kind (for example, according to the dictionary definition, that for "true" silk the filaments one starts from have to be $600-900$ meters long). But, as a substance, silk is silk, if it is the 
same chemical substance. (In fact silk is not a pure substance like water, but a natural kind of the same status as sand or blood.) The only sense in which perhaps substances have a common origin is relative to the Big Bang.

${ }^{42}$ In the sense used by Mellor (1977) and Quine (1977) following Goodman.

${ }^{43}$ See Putnam (1975, p. 196), where he discusses Engels's realism.

${ }^{44}$ See note 11.

45 This is a paraphrase of Putnam's account of Engels's account of natural kind concepts (Putnam, 1975, pp. 196-197).

46 The whole of thermodynamics "would collapse without the existence of this (fixed, but unattainable) lower limit of temperature" (A. Sommerfeld, Thermodynamics and Statistical Methods, Harper Torchbooks, 1956), as quoted by Ehrlich (1982).

${ }^{47}$ See Ehrlich (1982) in an article entitled "negative, infinite, and hotter than infinite temperatures", where references are given to the relevant physical literature. The systems for which such peculiar values of the temperature are possible are certain states of magneto spins.

${ }^{48}$ See Almog (1981b) for a discussion of how a stereotypical property can be considered a posteriori at one time and a priori at a later time (or the other way round). Of course, the fact that what we have discovered to hold with respect to the referent of a particular concept can be ascribed a priori or analytic status by convention is well known (for example Daum, 1982, on Schlick). Although this is by general consensus a trivial case of analyticity, I still think this aspect may add to confusions about necessities, in particular because (following Kripke) we don't discover what there is in other possible worlds; but we stipulate what is there (including any analytic properties we may like to include).

\section{REFERENCES}

Ackerman, D.: 1980, 'Natural Kinds, Concepts, and Propositional Attitudes', Midwest Studies Phil. 5, 469-486.

Almog, J.: 1981a, "Dthis and Dthat" Indexicality Goes Beyond That', Phil. Stud. 39, 347-359.

Almog, J.: 1981b, 'Indexicals, Demonstratives and the Modality Dynamics', Log. Anal. 24, 331-349.

Averill, E.: 1982, 'Essence and Scientific Discovery in Kripke and Putnam', Phil. Phenomenol. Res. 43, 253-257.

Campbell, J.: 1982, 'Extension and Psychic State: Twin Earth Revisited', Phil. Stud. 42, 67-89.

Cohen, L. J.: 1977, The Probable and the Provable, Clarendon Press, Oxford.

Daum, A.: 1982, 'Schlick's Empiricist Critical Realism', Synthese 52, 449-493.

Davies, M. and L. Humberstone: 1980, 'Two Notions of Necessity', Phil. Stud. 38, $1-30$.

Dummett, M.: 1973, Frege: Philosophy of Language, Duckworth, London, pp. 110-151.

Dummett, M.: 1978, Truth and Other Enigmas, Duckworth, London, pp. 420-430.

Dupré, J.: 1981, 'Natural Kinds and Biological Taxa', Phil. Rev. 90, 66-90. 
Ehrlich, P.: 1982, 'Negative, Infinite and Hotter than Infinite Temperature', Synthese 50, 233-277.

Fales, E.: 1982, 'Natural Kinds and Freaks of Nature', Phil. Sci. 49, 67-90.

Farrell, R.: 1983, 'Metaphysical Necessity and Epistemic Location', Austr. J. Phil. 61, 283-294.

Forbes, G.: 1981, 'An Anti-Essentialist Note on Substances', Analyses 41, 32-37.

Hare, R. M.: 1984, 'Supervenience', Arist. Soc., Suppl. Vol. 58, 1-16.

Hirsch, E.: 1982, The Concepts of Identity, Oxford University Press, New York.

Kripke, S. A : 1972, 'Naming and Necessity', in D. Davidson and G. Harman (eds.), Semantics of Natural Language, Reidel, Dordrecht; Harvard University Press, Mass., (1980).

Kursanov, D. N. et al.: 1959, 'The Present State of the Chemical Structural Theory', $J$. Chem. Educ. 29, 2-13.

Maccoll, A.: 1965, Space and Time in Chemistry, Lewis, London.

McGinn, C.: 1982, 'Realist Semantics and Content-Ascription', Synthese 52, 113-134.

McKay, F. and C. Stern: 1979, 'Natural Kind Terms and Standards of Membership', Ling. Phil. 3, 27-34.

Mellema, G.: 1981, 'On Quantifiers and Mass Terms', Am. Phil. Quart. 18, 165-170.

Mellor, D. H.: 1977, 'Natural Kinds', Brit. J. Phil. Sci. 28, 299-312.

Palacios, J.: 1964, Dimensional Analysis, MacMillan, London.

Paneth, F. A.: 1962, 'The Epistemological Status of the Chemical Concept of Element', Brit. J. Phil. Sci. 13, 1-14, 144-160.

Platts, M.: 1983, 'Explanatory kinds', Brit. J. Phil. Sci. 34, 133-148.

Putnam, H.: 1975, 'Mind, Language and Reality', Philosophical Papers, Volme 2, Cambridge University Press, Cambridge, U.K.

Putnam, H.: 1977, 'Meaning and Reference', in S. P. Schwartz (ed.), Naming, Necessity, and Natural Kinds, Cornell University Press, Ithaca and London, 1977, 1979.

Putnam, H.: 1978, Meaning and the Moral Sciences, Routledge and Kegan Paul, London.

Putnam, H.: 1981, Reason, Truth and History, Cambridge University Press, New York.

Putnam, H.: 1982, 'Realism and Reason', Philosophical Papers, Volume 3, Cambridge University Press, Cambridge, U.K.

Putnam, H.: 1983, 'Meaning Holism', typescript.

Quine, W. V.: 1977, 'Natural Kinds', in S. P. Schwartz (ed.), Naming, Necessity and Natural Kinds, Cornell University Press, Ithaca and London, pp. 155-175.

Salmon, N. U.: 1982, Reference and Essence, Basil Blackwell, Oxford.

Schwartz, S. P.: 1980, 'Natural Kinds and Nominal Kinds', Mind 89, 182-195.

Smith, P.: 1981, Realism and the Progress of Science, Cambridge University Press, New York.

Ter Meulen, A.: 1981, 'An Intensional Logic for Mass Terms', Phil. Stud. 40, 105-125.

Timmermans, J.: 1963, The Concept of Species in Chemistry, Chemical Publishing Co., New York.

Tye, M.: 1983, 'On the Possibility of Disembodied Existence', Austr. J. Phil. 61, $275-282$.

Unwin, N.: 1984, 'Substance, Essence and Conceptualism', Ratio 26, 41-53.

Van Brakel, J. and H. Vermeeren: 1981, 'On the Philosophy of Chemistry', Phil. Res. Arch. 7, 1405-1456. 
Weyl, H.: 1963, Philosophy of Mathematics and Natural Science, Appendix D: 'Chemical Valence and the Hierarchy of Structure', Atheneum, New York, pp. 266-275.

Wiggins, D.: 1980, Sameness and Substance, Basil Blackwell, Oxford.

Zemach, E. M.: 1976, 'Putnam's Theory of Reference of Substance Terms', J. Phil. 73, 116-127.

University of Utrecht

Dept. of Philosophy

P.O. Box 80.103

3508 TC Utrecht

The Netherlands 